\title{
Evaluation of Sustainability of Zhengzhou's Land Use
}

\author{
Nan Wang ${ }^{1} \&$ Shenghui $\mathrm{Li}^{1}$ \\ ${ }^{1}$ School of Economics and Management, Sichuan Agricultural University, Sichuan, China \\ Correspondence: Nan Wang, Room 48-4812, Hubei Centaline Company,Wuhan New World International Trade \\ Building 1, 568 Construction Avenue, Wuhan City, Hubei Province, China. Tel: 1-869-618-4551. E-mail: \\ 648336346@qq.com
}

Received: July 28, 2017

Accepted: September 12, 2017

Online Published: November 29, 2017

doi:10.5539/jsd.v10n6p214

URL: https://doi.org/10.5539/jsd.v10n6p214

\begin{abstract}
Land is not only a major space for human production and living, but also one of the most precious resources to humans. As a space carrier of urban construction, urban land resources constitute the part with the highest asset benefit among land resources, offering an essential space for economic reproduction, population reproduction and environment reproduction in urban areas. To sum up, urban land resources are the material basis, guaranteeing sustainability of urban development.

In this paper, changes of sustainability of land use in Zhengzhou City, Henan Province from 2011 to 2015 were analyzed so as to evaluate sustainability level of land use in Zhengzhou. Based on correlation analysis, resource, environment, economy and society were selected as four evaluation indexes, and their weights were determined. Then, the method of maximum was used to realize data normalization, and the comprehensive index value was computed. Finally, sustainability of Zhengzhou's land use was comprehensively evaluated. Taken as a whole, sustainability of Zhengzhou's land use was improving from 2011 to 2015, but the comprehensive sustainability level was still low, calling for further strengthening. From 2014 to 2015, the sustainability level of land use was still on the downward.
\end{abstract}

Keywords: sustainability evaluation of urban land use, correlation analysis, maximum method

\section{Introduction}

\subsection{Research Background and Significance}

With explosive growth of population and economy, the environmental pressure is increasing, among which land degradation has drawn worldwide attention, particularly driving scholars to study it from different perspectives. In China, land degradation is also worsening, which is mainly reflected as water and soil loss. In this paper, correlation analysis was employed to evaluate land use of Zhengzhou from 2011 to 2015. In recent years, the central government and the provincial government of Henan have subsequently put forward strategic ideas, including "Emergence of Central China" and "Emergence of Central Plains". In essence, emergence of Central Plains is to realize comprehensive and sustainable development of central plains, and sustainable development of Henan Province rests on sustainable development of local resources, environment, economy and society. As the provincial capital of Henan, Zhengzhou has gradually realized the importance of sustainable land use. However, impacted by both natural factors and human factors, such as growing population pressure, low economic development, and unreasonable development, Zhengzhou's land use sustainability still calls for improvement.

\subsection{Research Methodology}

In this paper, correlation analysis was adopted to evaluate the sustainability level of land use in Zhengzhou. Then, based on analysis results, measures to improve sustainability of Zhengzhou's land use were proposed.

To start with, evaluation indexes were selected in accordance with practical situations of the research area and connotation of sustainability evaluation. Next, correlation analysis was used to compute the correlation coefficient between different indexes. With the correlation coefficient, the weight of every index was determined. Finally, normalized results of the maximum value were multiplied with the weights to obtain the comprehensive evaluation value. The evaluation value was further analyzed to obtain the final conclusions.

\subsection{Overview of the Research Area}

Located in Central Plains, Zhengzhou is the provincial capital of Henan. With the Yellow River to the north, 
Zhengzhou borders Xuchang to the south, Kaifeng (capital city of seven dynasties) to the east, and Luoyang (capital city of nine dynasties) to the west. Being one of the earliest habitats of the Chinese nation and cradles of ancient Chinese civilization, Zhengzhou has a profound history. Spanning $34^{\circ} 16^{\prime} \sim 34^{\circ} 58 \mathrm{~N}$ latitude and $112^{\circ}$ $42^{\prime} \sim 114^{\circ} 14^{\prime}$ E longitude, Zhengzhou is in the middle latitude. Due to the geographical location, Zhengzhou experiences a warm and semi-humid continental monsoon climate, with cool, dry winters and hot, humid summers. The four seasons are distinct. The annual mean temperature of Zhengzhou is around $14.4^{\circ} \mathrm{C}$. July is the hottest, whose temperature averages at $33.5^{\circ} \mathrm{C}$; while January is the coldest, whose temperature averages at $-0.8^{\circ} \mathrm{C}$. The annual mean rainfall of the city is around $640.9 \mathrm{~mm}$. There are 220 frostless days. Throughout a year, the city receives around 2,400 hours of sunshine. Being a large city, Zhengzhou covers a total area of 744,620 hectares, of which 101,330 hectares are the urban area, and 26,240 hectares are the built-up area. Currently, Zhengzhou is divided into six urban districts, five county-level cities and one county, including Jinshui District, Erqi District, Zhongyuan District, Guancheng District, Mangshan District, Shangjie District, Gongyi District, Dengfeng City, Xingyang City, Xinmi City, Xinzheng City, and Zhongmu City.

\section{Index Selection}

\subsection{Selection Basis}

In accordance with the principle of scientificity, systematicness, predictability, hierarchy, dynamics and combination between internal and external factors, 12 factors influencing Zhengzhou's land are selected. These indexes could comprehensively reflect interdependence and mutual restriction among natural, economic and society factors in Zhengzhou.

\subsection{Index Selection}

\subsubsection{Selection of Resource Indexes and Environmental Factors}

Resources lay the material foundation for sustainability of land use. Therefore, in evaluating land use sustainability, one should first consider resource indexes. In the light of local conditions and relevant data, precipitation, arable land area, and domestic water consumption per capita were chosen as the resource indexes for this evaluation. As to environmental factors, they exert an influence on the natural land through different kinds of media. Particularly, its influence on land quality is obvious. If the same land is located under different environmental conditions, the land quality will be different, thus resulting in a great variation of land sustainability. Therefore, environmental indexes also play an important role in evaluating land use sustainability. In this paper, solid waste comprehensive use rate, industrial waste water discharge amount, and urban public green area per capita were selected as environmental indexes.

\subsubsection{Selection of Economic and Social Indexes}

Human activities are a major contributor to changes of land quality in that the former can directly influence sustainability of land use. So far, all kinds of land degradation have been associated with human activities. Therefore, social and economic indexes are decisive to evaluation of sustainable land use. Below is a list of different indexes selected in this paper: 
Table 1. Evaluation indexes of sustainability of Zhengzhou's land use

\begin{tabular}{|c|c|c|c|c|c|c|}
\hline & Year & 2011 & 2012 & 2013 & 2014 & 2015 \\
\hline \multirow{3}{*}{$\begin{array}{l}\text { Resource } \\
\text { indexes }\end{array}$} & Precipitation (mm) & 728.8 & 692.6 & 596.4 & 658.2 & 762.5 \\
\hline & Arable land ( $1,000 \mathrm{ha})$ & 330.14 & 330.7 & 329.8 & 328.53 & 327.4 \\
\hline & $\begin{array}{c}\text { Domestic water consumption } \\
\text { per capita }(\mathrm{L})\end{array}$ & 161.31 & 146 & 156 & 107.67 & 115 \\
\hline \multirow{3}{*}{$\begin{array}{l}\text { Environmental } \\
\text { indexes }\end{array}$} & $\begin{array}{c}\text { Solid waste comprehensive } \\
\text { utilization rate }(\%)\end{array}$ & 67.6 & 66.4 & 60.8 & 78.1 & 35.2 \\
\hline & $\begin{array}{c}\text { Industrial waste water } \\
\text { discharge amount }(10,000 \mathrm{t})\end{array}$ & 11354 & 12749 & 13013 & 12696 & 11155 \\
\hline & $\begin{array}{l}\text { Urban public green area per } \\
\text { capita (square meters) }\end{array}$ & 8 & 8.7 & 9.2 & 9.3 & 9.7 \\
\hline \multirow{3}{*}{$\begin{array}{l}\text { Economic } \\
\text { indexes }\end{array}$} & $\begin{array}{l}\text { Percentage of the tertiary } \\
\text { industry in GDP }(\%)\end{array}$ & 62.52 & 63.53 & 67.08 & 63.58 & 66.21 \\
\hline & GDP per capita (yuan) & 25474 & 30738.9 & 34068.9 & 40714 & 44231 \\
\hline & $\begin{array}{l}\text { Treatment fees of the urban } \\
\text { exhaust emissions }(10,000 \\
\text { yuan) }\end{array}$ & 23790.9 & 25296.9 & 31710 & 47821.1 & 55391 \\
\hline \multirow{3}{*}{ Social indexes } & $\begin{array}{c}\text { Population density } \\
\text { (person/square kilometers) }\end{array}$ & 878 & 882 & 886 & 890 & 894 \\
\hline & Engel coefficient $(\%)$ & 34 & 33.9 & 32.75 & 33.05 & 31.75 \\
\hline & $\begin{array}{l}\text { Total number of students at } \\
\text { school (10,000 persons) }\end{array}$ & 337.9873 & 461.7532 & 387.483 & $\begin{array}{c}403.714 \\
1\end{array}$ & $\begin{array}{c}329.662 \\
8\end{array}$ \\
\hline
\end{tabular}

\section{Results and Analysis}

\subsection{Determination of Index Weights}

In selecting indexes, it is found out that different indexes contribute differently to sustainability of land use. Therefore, it is necessary to determine weights of various indexes. In previous research, methods, like Delphi method and analytic hierarchy process (AHP), were usually adopted. However, these methods rely on experiences to a large extent and are influenced by human factors. In this research, the correlation coefficient among various indexes was used to determine the weight. The following part is about computing of the correlation coefficient:

1) Computing of the correlation coefficient: Operate the selected indexes in the SPSS and obtain the following correlation coefficient matrixes. See below: 
Table 2. Correlation coefficient matrix

\begin{tabular}{|c|c|c|c|c|c|c|c|c|c|c|c|c|}
\hline & $\mathrm{n} 1$ & n 2 & n 3 & n 4 & n 5 & n 6 & n 7 & n 8 & n 9 & $\mathrm{n} 10$ & n 11 & $\mathrm{n} 12$ \\
\hline $\mathrm{n} 1$ & 1 & & & & & & & & & & & \\
\hline $\mathrm{n} 2$ & 0.36 & 1 & & & & & & & & & & \\
\hline n3 & 0.24 & 0.82 & 1 & & & & & & & & & \\
\hline $\mathrm{n} 4$ & 0.52 & 0.57 & 0.17 & 1 & & & & & & & & \\
\hline n5 & 0.89 & 0.45 & 0.09 & 0.59 & 1 & & & & & & & \\
\hline n6 & 0.11 & 0.78 & 0.74 & 0.51 & 0.11 & 1 & & & & & & \\
\hline $\mathrm{n} 7$ & 0.33 & 0.41 & 0.10 & 0.63 & 0.15 & 0.73 & 1 & & & & & \\
\hline $\mathrm{n} 8$ & 0.11 & 0.90 & 0.90 & 0.47 & 0.07 & 0.95 & 0.53 & 1 & & & & \\
\hline n9 & 0.26 & 0.98 & 0.91 & 0.49 & 0.27 & 0.86 & 0.41 & 0.97 & 1 & & & \\
\hline $\mathrm{n} 10$ & 0.08 & 0.91 & 0.85 & 0.52 & 0.08 & 0.97 & 0.60 & 0.10 & 0.96 & 1 & & \\
\hline $\mathrm{n} 11$ & 0.11 & 0.88 & 0.60 & 0.75 & 0.24 & 0.90 & 0.80 & 0.88 & 0.86 & 0.92 & 1 & \\
\hline $\mathrm{n} 12$ & 0.47 & 0.56 & 0.05 & 0.54 & 0.81 & 0.06 & 0.21 & 0.18 & 0.36 & 0.22 & 0.46 & 1 \\
\hline
\end{tabular}

2) Determination of weights: Compute the weight based on the correlation efficient in Table 2 and the following equation.

$$
\mathrm{W}_{\mathrm{i}}=\overline{\mathrm{r}} / \sum \overline{\mathrm{r}}
$$

Where, the weight of every index can be obtained by dividing the mean value of the coefficient of the index and the coefficient index of the other indexes, and divide it with the respective mean value.

Table 3. Average and weight of the correlation coefficient between indexes

\begin{tabular}{cllllll}
\hline & $\mathrm{n} \mathrm{1}$ & $\mathrm{n} \mathrm{2}$ & $\mathrm{n} \mathrm{3}$ & $\mathrm{n} \mathrm{4}$ & $\mathrm{n} \mathrm{5}$ & $\mathrm{n} \mathrm{6}$ \\
\hline $\mathbf{r}$ & 0.31 & 0.69 & 0.49 & 0.52 & 0.34 & 0.61 \\
Weight & 0.05 & 1.08 & 0.78 & 0.08 & 0.05 & 0.95 \\
& $\mathrm{n} \mathrm{7}$ & $\mathrm{n} 8$ & $\mathrm{n} 9$ & $\mathrm{n} 10$ & $\mathrm{n} \mathrm{11}$ & $\mathrm{n} 12$ \\
$\mathbf{+}$ & 0.44 & 0.63 & 0.67 & 0.65 & 0.67 & 0.36 \\
Weight & 0.07 & 0.99 & 0.104 & 0.101 & 0.105 & 0.06 \\
\hline
\end{tabular}

\subsection{Data Normalization Results}

The method of maximum was used to normalize the raw. Among indexes selected, there were positive and negative indexes:

Equation for normalization of positive indexes:

$$
\mathrm{X}_{\mathrm{ij}}^{\prime}=\mathrm{X} / \max \left(\mathrm{x}_{\mathrm{ij}}\right) \quad(\mathrm{i}=1,2,3 \ldots \ldots)
$$

Equation for normalization of negative indexes:

$$
\mathrm{X}_{\mathrm{ij}}^{\prime}=1-\mathrm{X} / \max \left(\mathrm{x}_{\mathrm{ij}}\right) \quad(\mathrm{i}=1,2,3 \ldots \ldots)
$$


Table 4. Data normalization results

\begin{tabular}{rrrrrrrrr}
\hline & $\mathrm{n} 1$ & $\mathrm{n} 2$ & $\mathrm{n} \mathrm{3}$ & $\mathrm{n} 4$ & $\mathrm{n} 5$ & $\mathrm{n} 6$ & $\mathrm{n} \mathrm{7}$ & $\mathrm{n} \mathrm{8}$ \\
\hline 2011 & 0.21 & 0.20 & 0.24 & 0.22 & 0.19 & 0.18 & 0.19 & 0.15 \\
2012 & 0.20 & 0.201 & 0.22 & 0.22 & 0.21 & 0.19 & 0.197 & 0.18 \\
2013 & 0.17 & 0.20 & 0.24 & 0.20 & 0.21 & 0.20 & 0.21 & 0.19 \\
2014 & 0.19 & 0.20 & 0.16 & 0.25 & 0.21 & 0.21 & 0.197 & 0.23 \\
2015 & 0.22 & 0.19 & 0.17 & 0.11 & 0.18 & 0.22 & 0.21 & 0.25 \\
\hline & $\mathrm{n} 9$ & $\mathrm{n} 10$ & $\mathrm{n} 11$ & $\mathrm{n} \mathrm{12}$ & & & & \\
\hline 2011 & 0.13 & 5.45 & 4.866 & 0.18 & & & & \\
2012 & 0.14 & 3.79 & 4.88 & 0.24 & & & & \\
2013 & 0.17 & 5 & 5.05 & 0.201 & & & & \\
2014 & 0.26 & 4.98 & 5.00 & 0.21 & & & & \\
2015 & 0.301 & 4.95 & 5.21 & 0.17 & & & & \\
\hline
\end{tabular}

\subsection{Determination of the Comprehensive Index Value}

Calculate the comprehensive index value:

$$
\mathrm{IQI}=\sum \mathrm{W}_{\mathrm{i}} * \mathrm{~N}_{\mathrm{i}}
$$

The comprehensive index value can be calculated by multiplying the normalized results with the weights of various indexes.

Table 5. Results of the comprehensive index value

\begin{tabular}{cccccc}
\hline & 2011 & 2012 & 2013 & 2014 & 2015 \\
\hline Comprehensive index value & 6.34 & 6.67 & 6.81 & 7.22 & 7.04 \\
\hline
\end{tabular}

\subsection{Result Analysis}

From Fig. 3-1 show that the comprehensive index value of Zhengzhou is not high, but, on the whole, it is on the increase, despite of a downward trend found from 2014 to 2015. This suggests that sustainability of Zhengzhou's land use should be further strengthened.

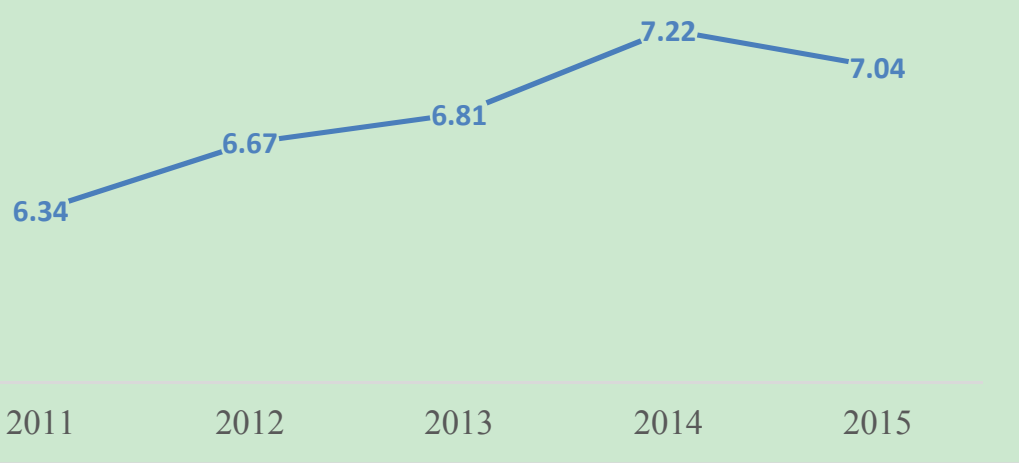

Figure 1. Comprehensive index value of Zhengzhou from 2011 to 2015

\section{Problems and Countermeasures}

\subsection{Problems Existing in Zhengzhou's Sustainable Land Use}

1) Zhengzhou is in severe shortage of water and land resources. In particular, its sewage treatment capability and pollutant recycling ability are poor. 
2) Zhengzhou is experiencing fast population growth, which exerts a heavy pressure on the environment.

3) The industrial structure is unreasonable, and the economic growth mode is calling for a change.

\subsection{Countermeasures to Improve Sustainability of Zhengzhou's Land Use}

1) Adjust the industrial structure, change the economic growth mode, and build a sustainable development system

Though Zhengzhou has accelerated adjustment of its industrial structure, the effects have been far from satisfactory. Problems such as low efficacy of industrial departments, unreasonable structure, a high proportion of traditional industries, lack of competitiveness, and slow development of the new-and high-tech industry have been popping up. As a hub city in the Program of "Emergence of Central Plains", Zhengzhou should speed up adjustment of its industrial structure, if it wants to get an edge over other large-and medium-sized enterprises in China. Meanwhile, it should drive industrialization through informatization, and make full use of the new and high technology to transform traditional industries to strengthen competitiveness of its pillar industries, and improve the industrial contribution to the local economic growth. Through acceleration of economic transformation and adjustment of the industrial structure and the urban-rural structure, a more environmentally-friendly national economic system featuring low resource consumption can be preliminarily shaped. During the urbanization process, Zhengzhou should also increase the utilization rate of land and water resources, and alleviate environmental pollution and ecological damage incurred by urbanization. Last but not least, transformation and upgrade of the industrial structure are also essential to Zhengzhou, through which pressure of industrial development on resources and environment can be eased, the economic structure can be further optimized, and consumption of resources and energies by economic development can be reduced.

2) Scientifically develop natural resources, strengthen their protection, and increase sustainability of resources

Development is the top priority to current China. However, without support of natural resources, development will be impossible. At present, water, land and mineral resources are limited in China. It is an imperative to strengthen protection of these limited resources by implementing guidelines, such as "protecting resources, saving and reasonably using resources", "integrity of development, utilization, protection and reproduction" as well as the paid resource use system and the reasonable compensation mechanism, advocating "whoever develops is responsible for the production, whoever damages is responsible for the restoration, and whoever uses is responsible for its compensation". In additional, capitalization of natural resources can also contribute to reasonable development of natural resources. Development of China's national economy and society cannot be separated from natural resources. Therefore, efforts should be made to integrate and protect all these natural resources. To be specific, protection of water resources should be strengthened; the land approval system should be tightened; development and protection of mineral resources should be further coordinated. All in all, protection and sustainable use of natural resources should reflect the unity among economic, social and environmental benefits. Only in this way can resource development, resource protection and economic construction achieve synchronous development.

\section{3) Speed up construction of a conservation-minded society}

First, technological advances should be capitalized on to further tap the potential of resources. The market mechanism and the economic methods should be given into full play to achieve efficient allocation of resources. A development path targeting at improvement of resource utilization efficiency and development of the resource-saving economy should be ushered in. Second, development and conservation should go side by side, with conservation at the core. Legislation efforts should be made to enhance enforcement of the resource-saving policies. Technology should play the role of guaranteeing feasibility of energy conservation policies. More importantly, economic policies should encourage formulation of the energy-saving guideline implementation mechanism. Based on the basic national policy of resource conservation, the economic growth mode should be fundamentally transformed to increase the resource utilization efficiency, alleviate the bottlenecks of resources and energies, and fasten establishment of a resource-saving national economic system. To achieve the goal, conservation and intensive utilization of land resources should be further advocated. The consumption structure should be further optimized. In particular, the whole society should be guided to join in efforts to save resources, protect environment, support green and renewable products, and follow a health, civilized and diligent lifestyle and consumption mode. Finally, excessive consumption and waste of resources should be strictly forbidden.

5) Vigorously develop the circular economy and realize sustainable resource utilization

Vigorous development of the circular economy and sustainable use of resources are a necessary requirement to implement the outlook on sustainable development. In accordance with the principle of "circular utilization, 
sustainable utilization" as well as "conservation, reutilization, and recycling", the current resource utilization model can be transferred from a traditional economic model featuring "resources - products - wastes" to the circular economy featuring "resources-products-wastes-renewable resources". At the core of the circular economy is comprehensive utilization and recycling of resources. At the same time, resource development should be guided on the track of refined processing and comprehensive utilization. Through extension of the industrial chain, resource utilization efficiency can be effectively improved, with fewer emissions of wastes. The government plays an important role in developing the circular economy. Policies beneficial to development of the circular energy should be introduced; technological R\&D should be intensified; and most importantly, a circular economic support system should be put in place.

6) Give priority to prevention, control emissions of pollutants, and do a good job in comprehensive treatment

The principle of "putting prevention in the first place and adopting comprehensive treatment" should be strictly stuck to. Pollution behaviors should be punished more severely to effectively reduce emissions of pollutants and achieve favorable results of pollution treatment. In major basins, regions and industries, the pollution discharge permit should be implemented. Those major polluters should be put under strict control to avoid damaging the local environment, polluting the local drinkable water and impairing the local air quality.

7) Implement ecological protection, optimize ecological environment and build an environmentally-friendly society

While adhering to the principle of "orderly development and priority of protection", Zhengzhou should strictly control unreasonable resource development activities, strengthen construction of the major ecological functional protection zones, and enhance protection of ecological resources, including water, land and wet lands. Also, more ecological protection projects and ecological city construction projects should be introduced for the sake of improving the local ecological quality, maintaining the ecological safety, upgrading the environment carrying capacity and building an environmentally-friendly society.

\section{Conclusions}

In this paper, sustainability of Zhengzhou's land use was adopted as the research object, and was evaluated from four perspectives, namely resources, environment, environment, economy and society. Based on analysis of the research results, problems existing in Zhengzhou's sustainable land uses were pointed out, and countermeasures to cope with these problems were proposed. Research findings of this paper suggest that sustainability of Zhengzhou's land use is calling for further improvement through a more harmonious interplay between economic development and ecological environment. In China, development comes first, but equality of quality is also important. As an effective means to the end, sustainable development relies on unity of ecological, economic and social benefits is indispensable for realization of sustainable.

\section{Acknowledgments}

In addition to the content of the citation in this paper, there are no other studies published or written by other individuals or groups. Thanks for the colleagues who helped me during the study. In addition, special thanks to li shenghui for helping me overcome many difficulties during the data collection process and helping me with the research. Finally, thanks to myself, after several months of efforts, finally got the harvest.

\section{References}

Bi, B. D. (2005). Land Economics. Beijing: China Renmin University Press.

Duan, Q. Y. (2009). A research of sustainable development on Zhengzhou's economy and ecology. Shaanxi: Northwest University.

Li, Z. N. (2010). Econometrics. Higher Education Press.

Statistical Communique on National Economic and Social Development of Henan Province in 2008[DB/OL]. National Knowledge Infrastructure (NKI), March 2015.

Wen, J. B. (2009). Government Work Report Delivered on the Second Session of the $11^{\text {th }}$ National People's Congress. Beijing: Renmin Publishing House, 3-6.

Zhengzhou Municipal People's Government. Communique on National Economic and Social Development of Zhengzhou City from 2011 to 2015[DB/OL]. NKI.

Zhengzhou Municipal Statistics Information Network. A brief introduction of demographic development in Zhengzhou[OL]. 02/2015.

Zhengzhou Survey Group of the Henan Branch of the National Bureau of Statistics of the PRC. (2015). 
Yearbook of Zhengzhou City from 2011 to 2015. Beijing: China Statistics Press, 62-79.

Zhengzhou Survey Group of the National Bureau of Statistics of the PRC. (2008). Yearbook of Zhengzhou City in 2014. Beijing: China Statistics Press, 62-79.

Zhong, W. F. (1996). Application of nonlinear planning to burnable poison configuration. Zhao W. Ppaer Collection of the $5^{\text {th }}$ Conference of the Operations Research Society of China. Xi'an: Xidian University Publishing House, 468-471.

\section{Copyrights}

Copyright for this article is retained by the author(s), with first publication rights granted to the journal.

This is an open-access article distributed under the terms and conditions of the Creative Commons Attribution license (http://creativecommons.org/licenses/by/4.0/). 